\title{
Relationship between suicide rate and economic growth and stock market in the People's Republic of China: 2004-20I3
}

This article was published in the following Dove Press journal:

Neuropsychiatric Disease and Treatment

8 December 2016

Number of times this article has been viewed

\author{
Honglei Yin ${ }^{1,2}$ \\ Lin $X u^{3}$ \\ Yechang Shao ${ }^{2,4}$ \\ Liping $\mathrm{Li}^{5}$ \\ Chengsong Wan ${ }^{2}$
}

'Department of Psychiatry, Nanfang Hospital, Southern Medical University, Guangzhou, People's Republic of

China; ${ }^{2}$ School of Public Health, Southern Medical University,

Guangzhou, People's Republic of

China; ${ }^{3}$ Department of Finance,

School of Economics and Commerce, South China University of Technology, Guangzhou, People's Republic of China; ${ }^{4}$ Guangdong Academy of Medical Sciences, Guangdong General Hospital, Guangzhou, People's Republic of China; ${ }^{5}$ Injury Prevention Research Center, Shantou University Medical College, Shantou, People's Republic of China
Correspondence: Chengsong Wan School of Public Health, Southern Medical University, 1023 South Shatai Road, Guangzhou, 5I05I5, People's Republic of China

Email gzwcs@126.com

Liping Li

Injury Prevention Research Center, Shantou University Medical College, 22 Xinling Road, Shantou 5 I 504I, People's Republic of China Email Ipli@stu.edu.cn
Objectives: The objective of this study was to estimate the features of suicide rate and its association with economic development and stock market during the past decade in the People's Republic of China.

Methods: Official data were gathered and analyzed in the People's Republic of China during the period 2004-2013. Nationwide suicide rate was stratified by four year age-groups, sex, urban/rural areas, and regions (East, Central, and West). Annual economic indexes including gross domestic product (GDP) per capita and rural and urban income per capita were all adjusted for inflation. Variation coefficient of market index (VCMI) was also included as an economic index to measure the fluctuation of the stock market. Negative binomial regression was performed to examine the time trend of region-level suicide rates and effects of sex, age, urban/rural area, region, and economic index on the suicide rates.

Results: Suicide rates of each age-group, sex, urban/rural area, and region were generally decreased from 2004 to 2013, while annual GDP per capita and rural and urban income per capita were generally increased by year. VCMI fluctuated largely, which peaked around 2009 and decreased after that time. Negative binomial regression showed that the decreased suicide rate in East and Central rural areas was the main cause of the decrease in suicide rate in the People's Republic of China. Suicide rate in the People's Republic of China for the study period increased with age and was higher in rural than in urban area, higher in males than in females, and the highest in the Central region. When GDP per capita increased by 2,787 RMB, the suicide rate decreased by 0.498 times. VCMI showed no significant relationship with suicide rate in the negative binomial regression.

Conclusion: Suicide rate decreased in 2004-2013; varied among different age-groups, sex, urban/rural areas, and regions; and was negatively associated with the economic growth in the People's Republic of China. Stock market showed no relationship with suicide rate, but this finding needs to be verified in a future study.

Keywords: suicide rate, economic indexes, stock market, People's Republic of China

\section{Introduction}

Suicide is a major public health issue worldwide. ${ }^{1}$ In the People's Republic of China, suicide was the fifth most common cause of death ${ }^{2,3}$ and the second most common external cause of death. ${ }^{4,5}$ Previous studies have shown decreasing trends in suicide in the People's Republic of China over the periods $1991-2000,{ }^{2,3} 1982-2005,{ }^{6}$ and 2006-2012. ${ }^{7}$ Early studies also showed that the characteristics of suicide rate in the People's Republic of China were different from those in Western countries. Previous studies have found that suicides in the People's Republic of China showed a unique 
sex difference, with more females than males, and the rate was also substantially higher in rural than urban Chinese communities. ${ }^{2,8-11}$ Mann et $\mathrm{al}^{12}$ found that $>90 \%$ of suicides in Europe, the USA, and other developed countries have a diagnosis of mental illness during lifetime, while in the People's Republic of China, mental illness accounted for only $\sim 50 \%$ of suicides. ${ }^{13}$ Therefore, social and economic determinants may be important factors for the suicide rate in the People's Republic of China.

A growing number of international studies have shown that rates of suicide were associated with economic activity. With the exception of Finland, which experienced an increase in suicide rate during an economic upswing between 1985 and 1990 and a decline during a subsequent period of recession, ${ }^{14}$ there were few empirical examples of suicide increasing during times of economic prosperity. Although research from Ireland showed no association between socioeconomic factors and suicide after accounting for time trends, ${ }^{15}$ most studies have suggested that suicide rates tend to decline during times of economic prosperity and increase during periods of recession. ${ }^{16-18}$ In a recent review of the population-level mental health effects of economic downturns, Zivin et al $^{19}$ inferred a positive association between economic crisis and the onset of psychopathology, including suicide. Nandi et $\mathrm{al}^{20}$ showed a negative association between monthly levels of economic activity and rates of suicide in New York City. However, Saurina et $\mathrm{al}^{21}$ did not find increase in working-aged females (16-64 years) living in municipalities with $\geq 10,000$ inhabitants to be associated with rising unemployment in any of the cases, which indicated that the relationship between suicide and economy is complicated and warrants further investigation.

Since the early 1980s, the People's Republic of China has experienced a very large economic growth, with an average annual gross domestic product (GDP) per capita growth rate of $8.6 \% .^{22}$ These rapid socioeconomic changes may influence people's attitude to life. It is, therefore, important to explore the relationship between the economic developments and the pattern of suicide in a rapidly changing society. There were very few studies about this topic in the People's Republic of China. A recent study found that the benefits of economic growth, such as higher employment and more educational opportunities for the rural population in particular, may have contributed to the reduced suicide rate in the People's Republic of China. ${ }^{23}$ Another study found that the decrease in suicide rate is correlated with the growth of economy in the People's Republic of China, ${ }^{6}$ but it did not systematically analyze the relationship between suicide rates and economic growth at the regional level in the People's Republic of China.
Based on the above-mentioned literature, the present study extended these previous studies to an investigation of possible explanatory factors and sources of geographic variation for the recent trends of suicides and economic indexes from the People's Republic of China in 2004-2013 and examined the geographic distribution characteristics about suicide and the relationship between suicide rates and economic changes. During the past two decades, the stock market fluctuated rapidly in the People's Republic of China, and there were always many suicide reports when the stock market fluctuated fiercely, which may be associated with suicide rates. Therefore, except for GDP per capita and annual urban and rural income per capita, the authors constructed a new economic index named variation coefficient of market index (VCMI) that can measure the fluctuation of the stock market. This study provides up-to-date information about the features of suicide and economics in the People's Republic of China and explores the socioeconomic determinants of suicide rates.

\section{Methods}

\section{Source of data}

\section{Annual suicide number and rate}

Data on the annual number of suicides and rate for the years 2004-2013 were obtained from the national disease surveillance points (DSPs) system, a population-based death registration system comprising 161 surveillance points (each point corresponds to one county or district) across 31 provinces nationwide (total population coverage of $6 \%$ or 73 million). This system expanded its number of surveillance points to 605 and total population coverage up to $24 \%$ or $>300$ million in 2013 . The cause of death in this sample registration system is determined by trained coders in hospitals and local Centers for Disease Control and Prevention staff for all deaths in each surveillance point. Previous studies have demonstrated good national and regional representativeness of the DSPs. ${ }^{8,24,25}$ Cases of death are enumerated through both hospitals and the local staff using household surveys, data exchange with police stations, the civil affairs department, and the maternal and children department. Decedents are counted as local residents if they have lived in the county for $>6$ months; otherwise, they are coded to their previous county of residence. The DSPs more accurately reflects total mortality, the broad cause of death distribution, and the geographic distribution of mortality compared with other mortality sources in the People's Republic of China. ${ }^{25}$

The yearly suicide number and suicide rates stratified by four year age-groups, sex, and region of the DSPs were extracted from the DSPs' death surveillance yearbook, a summary of the national population and mortality data, which is published yearly. 
Population catchments for each DSPs' surveillance point could be divided into urban and rural areas. First "districts" within each county were defined as "urban", and "counties" were defined as "rural". In total, there were 64 urban points and 97 rural points across the DSPs. Second, all points in the DSPs were allocated a regional classification based on the categorizations in the National Bureau of Statistics of the People's Republic of China as follows: "East" (Beijing, Tianjin, Hebei, Liaoning, Shanghai, Shandong, Guangdong, Jiangsu, Zhejiang, Fujian, Hainan), "Central” (Heilongjiang, Jilin, Shanxi, Hubei, Hunan, Anhui, Jiangxi, Henan), and "West" (Inner Mongolia, Guangxi, Chongqing, Sichuan, Guizhou, Yunnan, Tibet, Shaanxi, Gansu, Ningxia, Xinjiang, Qinghai). The data of this paper is gathered from the official dataset in People's Republic of China, so the authors didn't collect the data themselves and therefore there's no ethical approval or written informed consent involved.

\section{Annual economic indexes}

Official data of economic indexes during 2004-2013 were collected from the National Bureau of Statistics of the People's Republic of China. Nationwide data included GDP per capita, and the region-level data included GDP per capita in three regions (East, Central, and West) and annual income per capita in six areas (East urban, East rural, Central urban, Central rural, West urban, and West rural), all adjusted for inflation. In addition, the authors constructed a new index named VCMI, which can measure the annual fluctuation of stock market:

$$
\text { VCMI }=\frac{\begin{array}{c}
\text { Mean of daily closed price of Shanghai } \\
\text { (securities) composite in one specific year }
\end{array}}{\begin{array}{c}
\text { Standard deviation of daily closed price of } \\
\text { Shanghai (securities) composite in the same year }
\end{array}}
$$

All the economic indexes are presented by RMB, the Chinese currency. At the time of writing, the exchange rate was approximately US $\$ 1=6.35 \mathrm{RMB}$.

GDP is the sum of gross value added by all resident producers in the economy plus any product taxes and minus any subsidies not included in the value of the products. It is calculated without making deductions for depreciation of fabricated assets or for depletion and degradation of natural resources. The GDP per capita was defined as GDP divided by mid-year population. The annual income per capita refers to part of the revenue of all household cash income that can be used to arrange the family life.

\section{Statistical analysis}

Descriptive statistics were presented, including annual number of suicides and suicide rate per 100,000 persons for each of the four year age-, sex-, and region-specific groups. Nationwide and region-level GDP per capita and annual income per capita were all measured by the Chinese currency RMB and adjusted by inflation. Nonparametric KruskalWallis ANOVA was used to test numerical differences among three regions. As the data were too dispersed to use Poisson regression, the authors chose negative binomial regression to examine the change in the region-level suicide rates over time and the influence of age, sex, region, and economic index on the suicide rate. The influence of age, sex, region, and economic index on the suicide rate was analyzed using negative binomial regression model, ${ }^{26}$ with the stratified suicide number as the response variable, the natural logarithm of stratified DSPs' population as an offset, and the four year age-groups, sex, urban/rural area, and economic index as the explanatory variables. Time trends of suicide rate in different areas were also analyzed using negative binomial regression, with the stratified suicide number as the response variable, the natural logarithm of stratified DSPs' population as an offset, and year as an explanatory variable. To decrease the variation, GDP per capita in this analysis was converted to a unit of 1,000 RMB, and then transformed by the natural logarithm.

All statistical analyses were performed using SPSS version 21 (IBM Corporation, Armonk, NY, USA). All reported probabilities ( $P$-values) were two sided and those $<0.05$ were considered statistically significant.

\section{Results}

The following results were observed in this study:

1. Suicide rates of each age-group, sex, urban/rural area, and region were generally decreased from 2004 to 2013. Suicide rates in the People's Republic of China for the study period were higher in older age-groups compared with younger age-groups. Suicide rates were higher in rural than in urban areas, higher in males than in females, highest in the Central region, and almost the same in the East and West regions over the study period (Table 1 and Figure 1). There was a substantial regional variation in suicide rates over the study period (Table 1 and Figure 1).

2. Suicide rate decrease in rural areas, especially in East and Central rural areas, is an inherent structural cause of the People's Republic of China's suicide rate decrease. In this part, negative binomial regression revealed that the nationwide suicide rate significantly decreased by year ( $B=-0.06, P<0.0001)$. With respect to the suicide rates in the urban area $(B=-0.057, P<0.0001)$, the suicide rates in the rural areas showed greater decrease $(B=-0.066$, $P<0.0001)$. Among rural suicide rates, East and Central rural areas showed a significant decrease (East: $B=-0.104$, 
Table I Annual number of suicide, suicide rates, and suicide composition ratio in different groups from 2004 to 2013

\begin{tabular}{|c|c|c|c|c|c|c|c|c|c|c|c|c|}
\hline \multirow[t]{2}{*}{ Groups } & \multirow[t]{2}{*}{ Variables } & \multirow[t]{2}{*}{ Classification } & \multicolumn{10}{|c|}{ Years } \\
\hline & & & 2004 & 2005 & 2006 & 2007 & 2008 & 2009 & 2010 & 2011 & 2012 & 2013 \\
\hline \multirow[t]{2}{*}{ Total } & Total suicide rate $(1 / 100,000)$ & & 13.6 & 12.19 & 10.11 & 10.07 & 9.49 & 9.21 & 8.3 & 7.85 & 7.72 & 7.69 \\
\hline & Total number of suicides & & 9,681 & 8,926 & 6,673 & 7,199 & 7,013 & 6,913 & 6,534 & 6,078 & 5,963 & $|7,48|$ \\
\hline Urban & Number of suicides & Urban & 2,337 & 2,017 & 1,475 & 1,642 & 1,524 & 1,650 & 1,612 & 1,419 & $\mathrm{I}, 48 \mathrm{I}$ & 3,721 \\
\hline \multirow[t]{5}{*}{ and rural } & & Rural & 7,344 & 6,909 & 5,198 & 5,557 & 5,489 & 5,263 & 4,922 & 4,659 & 4,482 & 13,760 \\
\hline & Suicide rates $(1 / 100,000)$ & Urban & 9.78 & 8.4 & 6.93 & 6.69 & 5.59 & 6.19 & 5.41 & 4.6 & 4.81 & 5.29 \\
\hline & & Rural & 15.53 & 14.55 & 11.62 & 11.84 & 11.42 & 10.88 & 10.05 & 10.01 & 9.65 & 8.77 \\
\hline & Suicide composition & Urban & 0.241 & 0.226 & 0.221 & 0.228 & 0.217 & 0.239 & 0.247 & 0.233 & 0.248 & 0.213 \\
\hline & & Rural & 0.759 & 0.774 & 0.779 & 0.772 & 0.783 & 0.761 & 0.753 & 0.767 & 0.752 & 0.787 \\
\hline \multirow{6}{*}{$\begin{array}{l}\text { Males and } \\
\text { females }\end{array}$} & Number of suicides & Male & 5,214 & 4,848 & 3,681 & 3,970 & 3,797 & 3,795 & 3,645 & 3,365 & 3,305 & 10,017 \\
\hline & & Female & 4,467 & 4,078 & 2,992 & 3,229 & 3,216 & 3,118 & 2,889 & 2,713 & 2,658 & 7,464 \\
\hline & Suicide rates $(1 / 100,000)$ & Male & 14.32 & 13.26 & 10.92 & 10.88 & 10.96 & 9.91 & 9.07 & 8.54 & 8.4 & 8.65 \\
\hline & & Female & 12.85 & 11.67 & 9.26 & 9.23 & 8.89 & 8.49 & 7.49 & 7.14 & 7.02 & 6.7 \\
\hline & Suicide composition & Male & 0.539 & 0.543 & 0.552 & $0.55 I$ & 0.541 & 0.549 & 0.558 & 0.554 & 0.554 & 0.573 \\
\hline & & Female & 0.461 & 0.457 & 0.448 & 0.449 & 0.459 & $0.45 I$ & 0.442 & 0.446 & 0.446 & 0.427 \\
\hline Different & Number of suicides & $5-14 \mathrm{yr}$ & 86 & 78 & 66 & 68 & 63 & 36 & 50 & 50 & 50 & 115 \\
\hline \multirow[t]{11}{*}{ age-groups } & & $15-44 \mathrm{yr}$ & 3,313 & 2,915 & 2,099 & 2,275 & 2,133 & 2,077 & 1,869 & $\mathrm{I}, 773$ & 1,556 & 4,495 \\
\hline & & $45-64 \mathrm{yr}$ & 2,868 & 2,618 & 1,986 & 2,140 & 2,146 & $2,|3|$ & 2,065 & 1,885 & 1,950 & 5,973 \\
\hline & & $>65 \mathrm{yr}$ & $3,4 \mid 4$ & 3,325 & 2,532 & 2,716 & 2,661 & 2,669 & 2,550 & 2,375 & 2,407 & 6,898 \\
\hline & Suicide rates $(1 / 100,000)$ & $5-14 \mathrm{yr}$ & 1.01 & 0.9 & 0.59 & 0.64 & 0.63 & 0.42 & 0.55 & 0.63 & 0.63 & 0.48 \\
\hline & & I5-44 yr & 9.15 & 7.99 & 6.24 & 6.31 & 5.74 & 5.54 & 4.88 & 4.66 & 4.18 & 4.38 \\
\hline & & $45-64 \mathrm{yr}$ & 19.63 & 17.82 & 14.42 & 14.03 & 13.16 & 11.86 & 10.41 & 9.44 & 9.53 & 9.13 \\
\hline & & $>65 \mathrm{yr}$ & 60.92 & 59.03 & 47.41 & 45.9 & 42.23 & 42.23 & 38.14 & 32.95 & 32.91 & 30.33 \\
\hline & Suicide composition & $5-14 \mathrm{yr}$ & 0.009 & 0.009 & 0.010 & 0.009 & 0.009 & 0.005 & 0.008 & 0.008 & 0.008 & 0.007 \\
\hline & & I5-44 yr & 0.342 & 0.326 & 0.314 & 0.316 & 0.305 & 0.300 & 0.286 & 0.291 & 0.261 & 0.257 \\
\hline & & $45-64 \mathrm{yr}$ & 0.296 & 0.293 & 0.297 & 0.297 & 0.306 & 0.308 & 0.316 & 0.310 & 0.327 & 0.342 \\
\hline & & $>65 \mathrm{yr}$ & 0.353 & 0.372 & 0.379 & 0.377 & 0.380 & 0.386 & 0.390 & 0.390 & 0.404 & 0.395 \\
\hline \multirow[t]{9}{*}{ Three areas } & Number of suicides & East & 3,064 & 2,980 & 2,252 & 2,328 & 2,318 & 2,365 & 2,130 & I,9|I & 2,003 & 6,041 \\
\hline & & Central & 4,107 & 3,742 & 2,969 & 3,031 & 2,985 & 2,855 & 2,789 & 2,699 & 2,569 & 7,566 \\
\hline & & West & 2,510 & 2,204 & ।,452 & $\mathrm{I}, 840$ & 1,710 & 1,693 & 1,615 & I,468 & 1,391 & 3,874 \\
\hline & Suicide rates $(1 / 100,000)$ & East & 11.68 & 11.32 & 8.96 & 8.68 & 8.21 & 8.24 & 6.92 & 6.33 & 6.67 & 6.89 \\
\hline & & Central & 16.52 & 15.02 & 12.77 & 12.11 & 11.75 & 11.02 & 10.46 & 9.98 & 9.49 & 9.18 \\
\hline & & West & $|2.5|$ & 10.88 & 8.24 & 9.38 & 8.43 & 8.3 & 7.57 & 7.28 & 6.92 & 6.79 \\
\hline & Suicide composition & East & 0.316 & 0.334 & 0.337 & 0.323 & 0.331 & 0.342 & 0.326 & 0.314 & 0.336 & 0.346 \\
\hline & & Central & 0.424 & 0.419 & 0.445 & 0.421 & 0.426 & 0.413 & 0.427 & 0.444 & 0.431 & 0.433 \\
\hline & & West & 0.259 & 0.247 & 0.218 & 0.256 & 0.244 & 0.245 & 0.247 & 0.242 & 0.233 & 0.222 \\
\hline
\end{tabular}

Abbreviation: $y r$, years.

$P<0.01$; Central: $B=-0.093, P<0.05)$. Therefore, the authors inferred that the suicide rate decrease in the rural areas, especially in East and Central rural areas, is the main cause of the People's Republic of China's suicide rate decrease (Table 2).

3. Nationwide and region-level GDP per capita and annual income per capita were generally increased by year, while VCMI showed a peak around 2008. GDP per capita and annual urban and rural income per capita had almost the same trend: highest in the East area and lowest in the West area (GDP per capita: $\chi^{2}=14.2, P=0.001$; rural income per capita: $\chi^{2}=11.9, P=0.003$; urban income per capita: $\chi^{2}=9.5, P=0.009$; Table 3 and Figure 2). VCMI fluctuated largely, peaked around 2008, and decreased after that time (Table 3 and Figure 3).
4. The suicide rate was higher in older age individuals, males, rural area, and Central region of the People's Republic of China and negatively correlated with GDP per capita. VCMI showed no significant relationship with the suicide rate. Negative binomial regression showed that suicide rates were $30.2 \%$ higher in the Central region (relative risk [RR]: 1.302, 95\% confidence interval [CI]: 1.038-1.634) and 29.9\% higher in the West region (RR: $1.299,95 \%$ CI: 1.034-1.633) compared with the East region (Table 4). The rates of suicide in the rural areas were approximately double (RR: $1.778,95 \%$ CI: 1.476-2.141) compared with the urban areas, and there were significantly higher rates of suicide in males (RR: 1.217, 95\% CI: 1.011-1.464) than in females (Table 4). It is worth mentioning that the suicide rate gradually increased with age. People older 


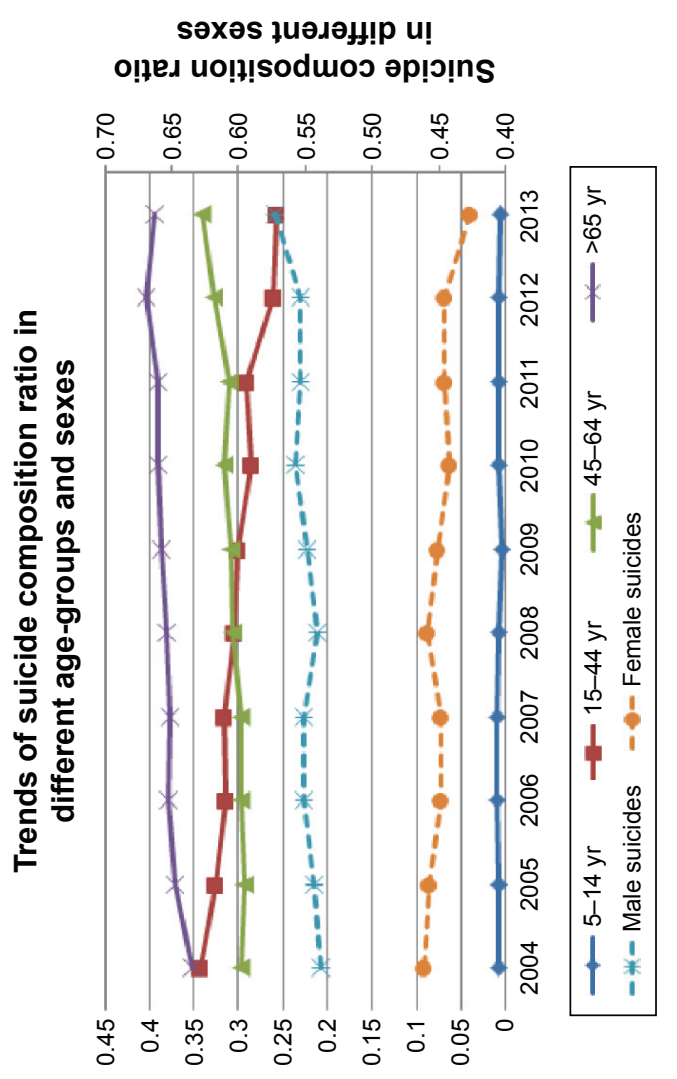

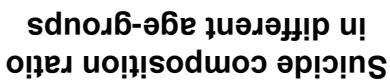

(000‘00 L/L) eәje jednd pue uequn u! sәje. әp!̣!ns

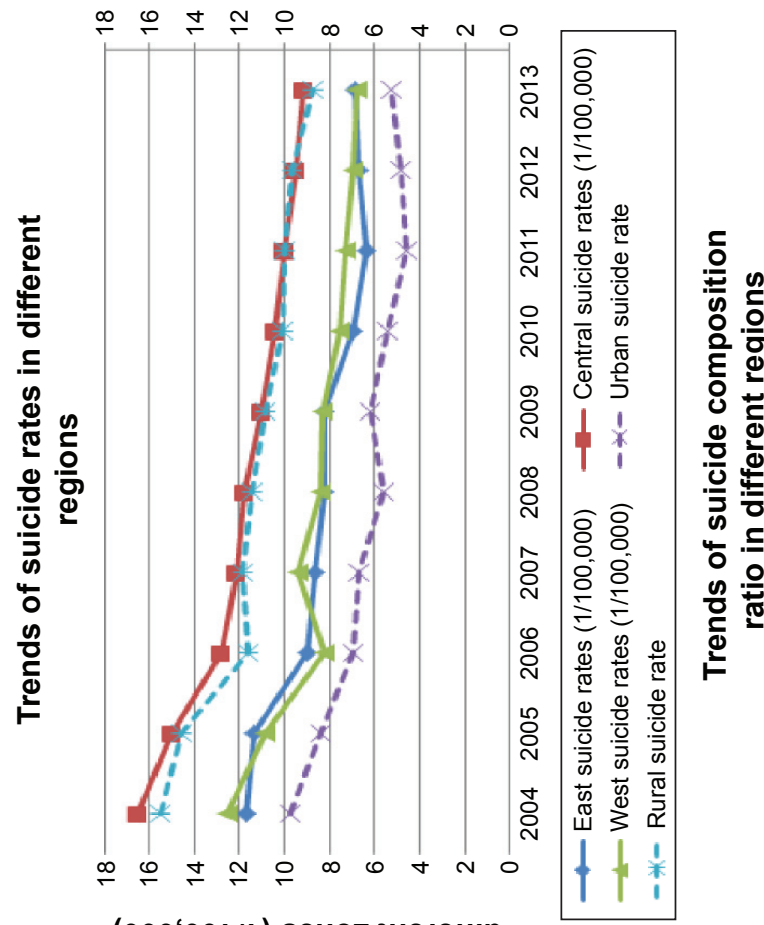

(000‘00 L/L) sәuoz ұนәرән!p

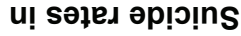

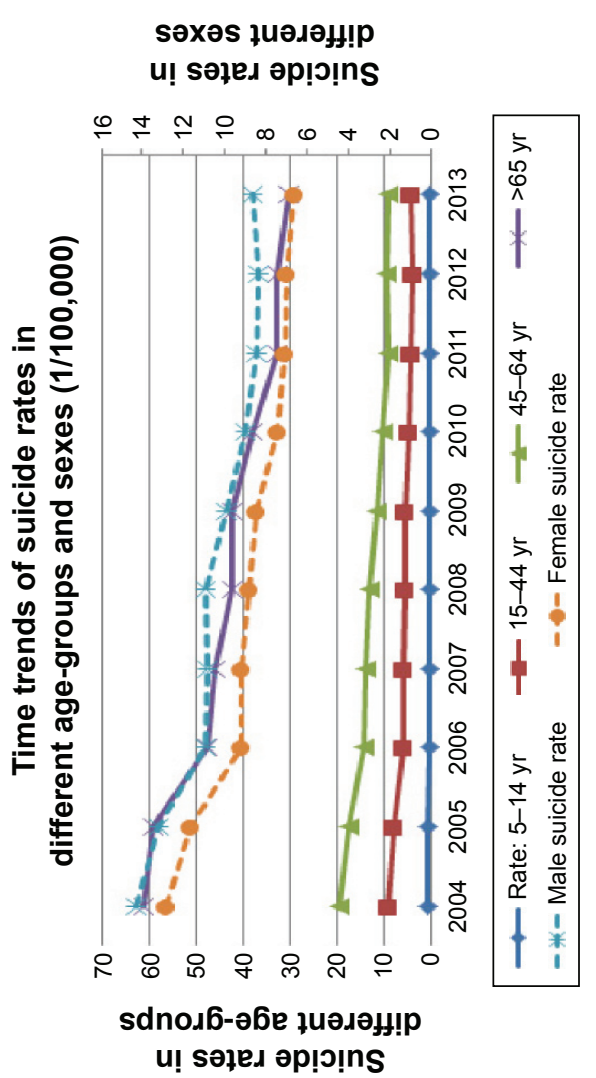

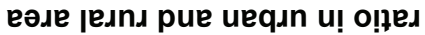
uo!t!soduos әp! ग!ns

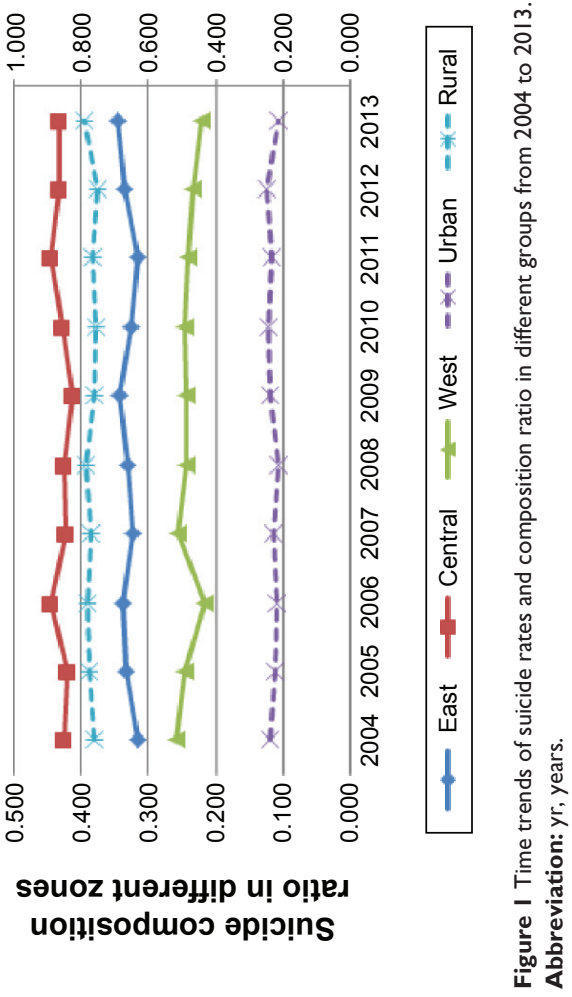


Table 2 Change in the region-level suicide rates over time

\begin{tabular}{|c|c|c|c|c|c|}
\hline \multirow[t]{2}{*}{ Model } & \multirow[t]{2}{*}{ Parameters } & \multirow[t]{2}{*}{ B } & \multirow{2}{*}{$\begin{array}{l}\text { Standard } \\
\text { deviation }\end{array}$} & \multicolumn{2}{|l|}{$95 \% \mathrm{Cl}$} \\
\hline & & & & Upper & Lower \\
\hline \multirow[t]{2}{*}{ Total } & Const & -8.417 & $0.099 *$ & -8.611 & -8.225 \\
\hline & Year & -0.080 & $0.016 *$ & -0.112 & -0.049 \\
\hline \multirow[t]{2}{*}{ Urban } & Constant & -8.158 & $0.140 *$ & -8.433 & -7.884 \\
\hline & Year & -0.075 & $0.023^{* *}$ & -0.119 & -0.031 \\
\hline \multirow[t]{2}{*}{ Rural } & Constant & -8.775 & $0.138 *$ & -9.045 & -8.505 \\
\hline & Year & -0.091 & $0.022^{*}$ & -0.134 & -0.047 \\
\hline \multirow[t]{2}{*}{ West rural } & Constant & -9.121 & $0.238^{*}$ & -9.588 & -8.654 \\
\hline & Year & -0.07 & 0.038 & -0.145 & 0.005 \\
\hline \multirow[t]{2}{*}{ West urban } & Constant & -8.273 & $0.244^{*}$ & -8.751 & -7.795 \\
\hline & Year & -0.083 & $0.039 * * *$ & -0.16 & -0.006 \\
\hline \multirow[t]{2}{*}{ Central rural } & Constant & -8.636 & $0.233^{*}$ & -9.092 & -8.179 \\
\hline & Year & -0.093 & $0.037^{* * *}$ & -0.166 & -0.021 \\
\hline \multirow[t]{2}{*}{ Central urban } & Constant & -7.786 & $0.244^{*}$ & -8.265 & -7.308 \\
\hline & Year & -0.074 & 0.039 & -0.151 & 0.003 \\
\hline \multirow[t]{2}{*}{ East rural } & Constant & -8.630 & $0.246 *$ & -9.112 & -8.147 \\
\hline & Year & -0.104 & $0.040^{* *}$ & -0.181 & -0.026 \\
\hline \multirow[t]{2}{*}{ East urban } & Constant & -8.572 & $0.238^{*}$ & -9.040 & -8.105 \\
\hline & Year & -0.068 & 0.038 & -0.143 & 0.007 \\
\hline
\end{tabular}

Notes: Dependent variable: stratified number of suicide. Offset $=\ln$ (stratified population of DSPs). *P-value $<0.001$. $* * P$-value $<0.01$. ***P-value $<0.05$.

Abbreviations: $\mathrm{Cl}$, confidence interval; DSPs, disease surveillance points.

than 65 years showed the highest rate of suicide (RR: 64.890, 95\% CI: 49.255-85.487), while those within 45-64 years showed moderate-higher rate of suicide (RR: 20.079, 95\% CI: 15.274-26.394). Those within 15-44 years also showed higher rate of suicide (RR: 9.566, 95\% CI: 7.280-12.569) relative to the age-group 5-14 years. Ln(GDP per capita 1,000 RMB) had a significant negative effect on the suicide rates (RR: 0.502, 95\% CI: 0.375-0.673), and when $\ln$ (GDP per capita $1,000 \mathrm{RMB}$ ) increased by one unit, that is to say, when GDP per capita was increased by 2,787 RMB (e×1,000), the suicide rate decreased by 0.498 times. VCMI did not show a significant effect on suicide rates (Table 4).

\section{Discussion}

This study investigated time trends and regional differences in suicide in the People's Republic of China for the period 2004-2013 and found a general decrease in the suicide rate, which was consistent with previous studies for earlier periods. ${ }^{2,3,27}$ In this study, suicide rate and composition were both higher in males than females, which were consistent with some recent studies in the People's Republic of China $^{7,28,29}$ and many previous studies in Western countries, which showed that the male:female ratio of completed suicide is usually $>2$ (eg, Australia, the USA, and the UK) and in some cases $>3$ (eg, Russia, Kazakhstan, Ukraine, and Belarus). ${ }^{30}$ Meanwhile, the suicide rate was higher in the rural area than in the urban area in this study, which was also consistent with some previous studies. ${ }^{2,10}$ The rural:urban ratio was 1.905 after controlling for sex, age, and regions in this study, compared with previous studies where this ratio was $2.13^{7}$ and some earlier studies that showed this ratio $>3 .^{2,10}$

Phillips et al first analyzed the suicide data of the People's Republic of China in 2002 and found a very special "Chinesestyle suicide mode" with higher suicide rate in the rural area than in the urban area and in females than in males, which was exactly the opposite to that in Western countries. ${ }^{2}$ With the acceleration of urbanization and industrialization, more and more people went to cities, and as the population migrated, females gradually got rid of the unequal treatment in male chauvinists and obtained more opportunity to elevate their education level; consequently, the rural:urban ratio of suicide rate and suicide rate of females decreased by year. So as described earlier, the present study and many recent studies about suicide in the People's Republic of China found gradually decreased rural:urban ratio of suicide rates and higher suicide rates in males than in females.

Table 3 Nationwide and region-level economic indexes of the People's Republic of China from 2004 to 2013

\begin{tabular}{|c|c|c|c|c|c|c|c|c|c|c|c|}
\hline \multirow[t]{2}{*}{ Year } & \multirow{2}{*}{$\begin{array}{l}\text { GDP } \\
\text { per capita }\end{array}$} & \multirow[t]{2}{*}{ VCMI } & \multicolumn{3}{|c|}{ GDP per capita } & \multicolumn{3}{|c|}{ Rural income } & \multicolumn{3}{|c|}{ Urban income } \\
\hline & & & East & Central & West & East & Central & West & East & Central & West \\
\hline 2004 & $12,400.0$ & 0.10 & $19,7 \mid 4.7$ & $9,294.6$ & $8,024.3$ & 4,091.I & $2,7 \mid 4.0$ & $2,165.7$ & II,559.4 & $7,849.0$ & $8,052.6$ \\
\hline 2005 & $14,006.9$ & 0.06 & $22,865.9$ & $10,954.6$ & $9,322.6$ & $4,449.2$ & $2,924.0$ & $2,347.9$ & $12,755.0$ & $8,597.0$ & $8,615.5$ \\
\hline 2006 & $16,067.4$ & 0.19 & $25,926.4$ & $|2,496|$. & $|0,84| .3$ & $4,821.6$ & $3,205.1$ & $2,508.3$ & $14,076.7$ & $9,502.6$ & $9,407.6$ \\
\hline 2007 & $18,780.7$ & 0.24 & $29,080.9$ & $14,423.5$ & $12,586.0$ & $5,206.9$ & $3,581.0$ & $2,806.1$ & $15,286.5$ & $10,566.1$ & $10,480.3$ \\
\hline 2008 & $20,851.9$ & 0.34 & $31,831.9$ & $16,347.2$ & $14,545.2$ & $5,564.4$ & $3,927.3$ & $3,080.7$ & $16,367.8$ & II,338.7 & II,347.I \\
\hline 2009 & $22,800.0$ & 0.16 & $34,529.0$ & $18,00 \mid .9$ & $16,164.4$ & $6,070.7$ & $4,255.0$ & $3,364.3$ & $17,988.2$ & $|2,4| 3 . \mid$ & $12,492.5$ \\
\hline 2010 & $25,985.6$ & 0.08 & $38,689.0$ & $21,143.5$ & $19,187.3$ & $6,666.6$ & $4,759.3$ & $3,765.5$ & $19,399.6$ & I3,332.| & $|3,4| 2.4$ \\
\hline 2011 & $29,050.8$ & 0.09 & $42,706.8$ & $24,292.6$ & $22,319.6$ & $7,493.9$ & $5,367.9$ & $4,256.1$ & $20,895.1$ & $|4,5| 3.5$ & $14,608.9$ \\
\hline 2012 & $31,086.5$ & 0.06 & $45,146.0$ & $26,242.1$ & $24,580.9$ & $8,244.9$ & $5,959.4$ & $4,760.1$ & $22,829.5$ & I5,996.3 & $16,160.5$ \\
\hline 2013 & $33,191.9$ & 0.05 & $47,980.2$ & $27,905.7$ & $26,550.8$ & $8,996.2$ & $6,941.2$ & $5,670.3$ & $23,549.0$ & I7,I49.I & $17,118.1$ \\
\hline$\chi^{2}$ & & & $\mid 4.2^{*}$ & & & $11.9 *$ & & & $9.5^{*}$ & & \\
\hline
\end{tabular}

Notes: Both GDP and income per capita are adjusted by inflation and both units are RMB. ${ }^{*}$-value $<0.0$ I.

Abbreviations: GDP, gross domestic product; VCMI, variation coefficient of market index. 


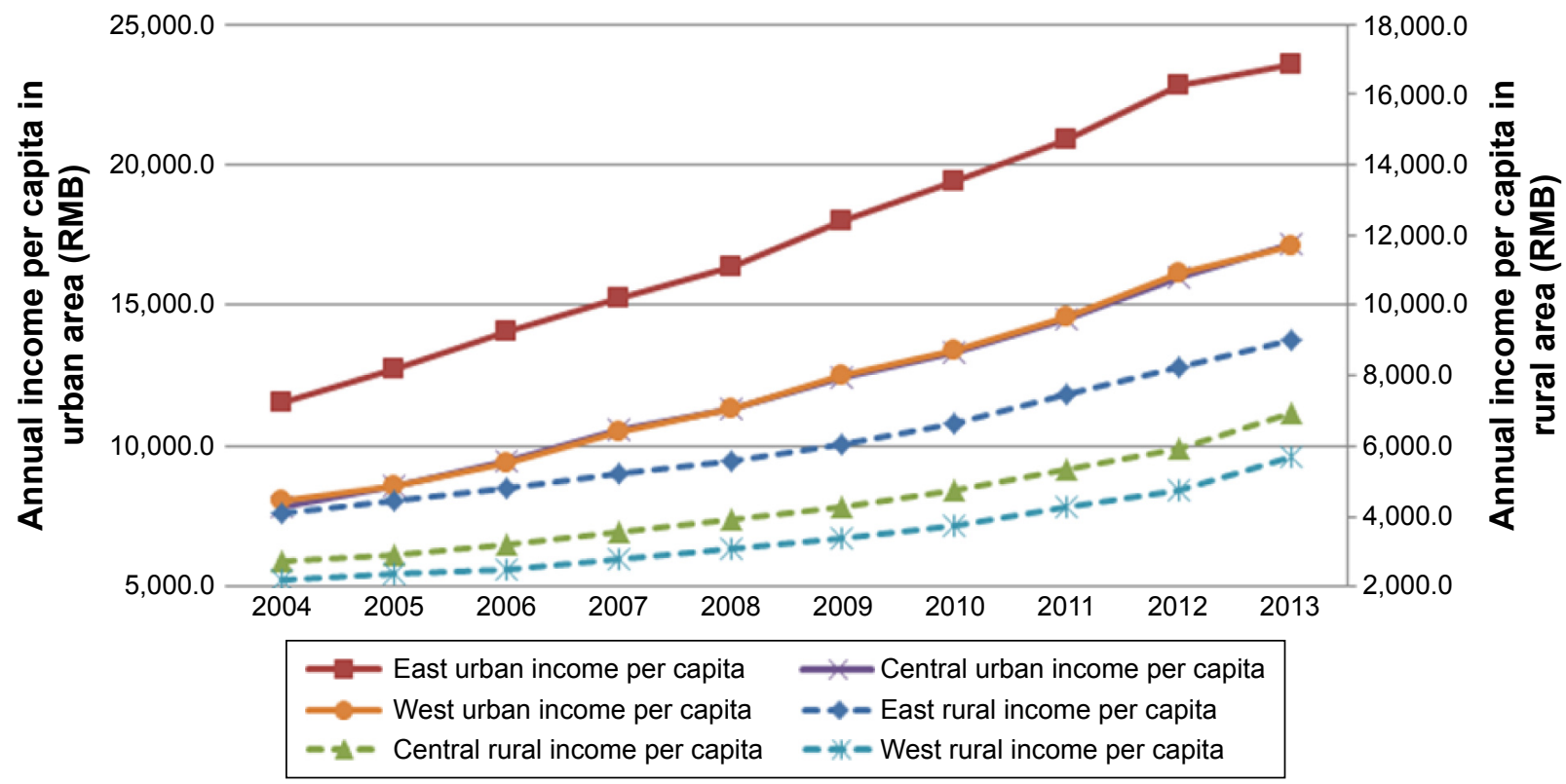

Figure 2 Time trends of region-level annual income per capita in the People's Republic of China from 2004 to 2013.

Additionally, suicide rates in the People's Republic of China for the study period were higher in older age-groups compared with younger age-groups. This finding was not consistent with previous studies that reported higher rates of suicide among young adults aged 15-34 years, particularly for rural females. ${ }^{2,4}$ This decrease in young adult suicide rates may be associated with commensurate increases in economic and educational opportunities and greater ideological emancipation for young adults. Meanwhile, because of emotion loss and economic pressure, people older than 65 years in the People's Republic of China have the highest suicide rate.

This study also showed substantial geographic variation in suicide across the People's Republic of China's major geographic regions. Central China had the highest suicide rates, which was $\sim 1.5$-fold of East zone, while the suicide rates were almost the same in the East and West zones, which was consistent with the findings of a recent study ${ }^{7}$ and another previous study, which also found the highest

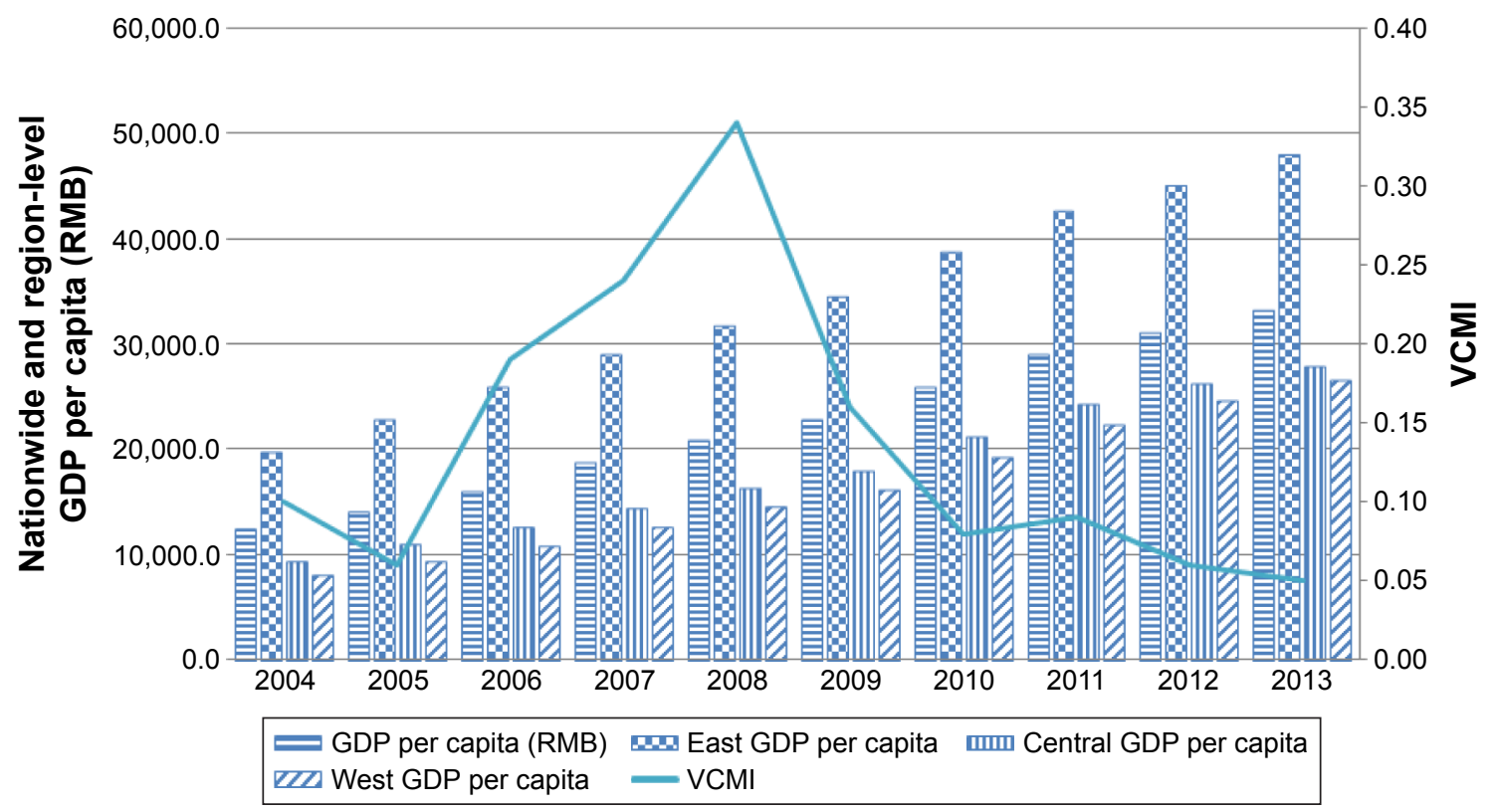

Figure 3 Time trends of GDP per capita and VCMI in the People's Republic of China from 2004 to 2013.

Abbreviations: GDP, gross domestic product; VCMI, variation coefficient of market index. 
Table 4 Negative binomial regression model to examine the influence of age, sex, region, and economic indexes on the suicide rate

\begin{tabular}{lll}
\hline Parameters & RR (95\% Cl) & P-value \\
\hline Zone (ref: East) & $\mathrm{I}$ & \\
Zone = West & $\mathrm{I} .299(\mathrm{I} .034-1.633)$ & 0.025 \\
Zone = Central & $\mathrm{I} .302(\mathrm{I} .038-1.634)$ & 0.022 \\
Sex (ref: female) & $\mathrm{I}$ & \\
Sex = male & $\mathrm{I} .217(\mathrm{I} .0 \mathrm{II}-\mathrm{I} .464)$ & 0.038 \\
Region (ref: urban) & $\mathrm{I}$ & \\
Region = rural & $\mathrm{I} .778(\mathrm{I} .476-2.14 \mathrm{I})$ & $<0.000 \mathrm{I}$ \\
Age (ref: 5-I4 yr) & $\mathrm{I}$ & \\
Age $=$ I5-44 yr & $9.566(7.280-12.569)$ & $<0.000 \mathrm{I}$ \\
Age $=45-64$ yr & $20.079(15.274-26.394)$ & $<0.000 \mathrm{I}$ \\
Age $=>65$ yr & $64.890(49.255-85.487)$ & $<0.000 \mathrm{I}$ \\
In(GDP per capita I,000 RMB) & $0.502(0.375-0.673)$ & $<0.000 \mathrm{I}$ \\
VCMI & $0.759(0.267-2.157)$ & 0.605 \\
\hline
\end{tabular}

Notes: Dependent variable $=$ stratified number of suicide. Offset $=$ the natural logarithm of stratified DSPs' population. Model = zone, urban/rural area, age, sex, In(GDP per capita I,000 RMB) and VCMI.

Abbreviations: RR, relative risk; yr, years; GDP, gross domestic product; VCMI, variation coefficient of market index; DSPs, disease surveillance points.

suicide rate in the Central rural area. ${ }^{4}$ Suicide rate decrease in rural areas, especially in East and Central rural areas, is an inherent structural cause of the People's Republic of China's suicide rate decrease. A recent publication in the Lancet also shows a tenfold variance in age-adjusted suicide rates for both males and females across 33 provinces (including HK and Macao) in the People's Republic of China. ${ }^{31}$ Meanwhile, the economic indexes, including GDP per capita, urban income per capita, and rural income per capita, also showed huge geographic variation. All these economic indexes were highest in the East area. GDP and rural income per capita were higher in the Central area than that in the West area, while urban income per capita remained almost the same in these two areas. Economic factors may act together with traditional culture and geographic factors to influence the suicide rates, so it is very important to make different suicide prevention and control policies for different regions.

The rapid economic growth has been the theme over the past three decades in the People's Republic of China, and economic reform has brought about significant social and value changes to the nation. In this study, GDP per capita showed significant effect on suicide rates, and when GDP per capita was increased by 2,787 RMB, the suicide rates decreased by 0.498 times. The People's Republic of China's fast growing economy in the past few decades did not come with increased suicide rates, and instead, as the GDP per capital, rural income per capita, and urban income per capita increased rapidly, the suicide rates in the People's Republic of China consistently went down over the years for all agegroups, for all the three regions, for both rural and urban populations, and for both males and females. Similar findings have also been documented in other studies. ${ }^{6,32}$ The traditional postulation that economic growth leads to high suicide rates in society is challenged by the current Chinese data as well as some Western data in previous studies. ${ }^{33,34}$

In addition, the authors should pay attention to the stock market. The results showed a peak of VCMI around 2008, but it decreased later. The People's Republic of China's stock market emerged in 1991 and developed no more than 20 years, which is a relatively short but critical period. After a number of ups and downs in the stock market callable bullbear contracts conversion, especially the 2007-2008 stock market crash, which resulted from the decrease in stamp duty in May 31, 2007, the People's Republic of China's stock market fluctuated largely. Such a sharp volatility of the stock market was beyond the risk tolerance of many investors; hence, a lot of suicides occurred due to investment failure. As more than $90 \%$ of the People's Republic of China's stock market investors were irrational retail investors, coupled with the "retail herding" effect and levers such as stock index futures and margin trading, the People's Republic of China's stock market was just like a casino. Once the investments failed, the investors easily lost control to commit suicides, resulting in increased suicide rates; thus, the greater the stock market volatility, the higher the suicide rate.

In this study, VCMI showed no effect on the suicide rate in the negative binomial regression model. This result is consistent with one study that found that fluctuations in the stock market, represented by stock market volatility, do not influence the rates of violent suicide at the population level in New York City, ${ }^{20}$ but not with numerous reports of suicide induced by losses in stock market wealth in recent years and one study that found that the value of the Nikkei Stock Average related to suicide among males in Japan. ${ }^{35}$ One potential explanation is that there are not enough people who invested in the stock market to detect fluctuations in incidence rates. In the People's Republic of China, people who invested in the stock market may be mostly male urban citizens. Alternatively, a sufficient causal mechanism for suicide may be multifactorial, and losses in wealth, including financial assets, may represent one component of a sufficient cause for suicide. According to a qualitative analysis of 62 cases of suicide involving economic strains, the reason for suicide frequently involved multiple comorbid stressors, such as economic losses and strain in a relationship with a significant other. ${ }^{36}$ Finally, it is possible that fluctuations 
in the stock market are decoupled from changes in wealth at the individual or ecologic level through, for example, practices such as short sales of stocks and bonds. Owing to the limitation of data that monthly or quarterly suicide rates were not available, the authors can only do a rough analysis using annual suicide rates and VCMI, but the present study laid a foundation for further studies.

\section{Limitations}

There were some limitations to the present analysis. First, suicide is influenced by many social factors, including marital status, unemployment, perceived or actual state of health of people who commit suicide, and so on. In this study, marital status and the unemployment rate were not available. Further studies should take more factors into consideration than the present study did. Second, although the authors have a clear negative correlation between economic growth and suicide rates, the authors cannot confirm direct causal relationship between economic growth and decline in suicide rates as the confounding factors were unknown and the authors cannot control them in this study. Third, the relationship between stock market and suicide may be better examined in a specific group who invested in the stock market.

\section{Conclusion}

The present study made an update to the trend and geographic distribution of suicide in the People's Republic of China, explored the relationship between suicide rates and economic indexes, and made a preliminary analysis about the relationship between suicide rate and stock market. However, additional work is necessary to address several unanswered questions, including which mechanisms link economic conditions to suicide.

\section{Acknowledgments}

The authors would like to thank Chunquan Ou of Department of Biostatistics, School of Public Health, Southern Medical University, for contributions to data analysis. Thanks also to Linhong Wang of Chinese Center for Disease Control and Prevention and Yaogui Lu of Injury Prevention Research Center, Shantou University Medical College, for their help with the data source in the present study.

\section{Disclosure}

The authors report no conflicts of interest in this work.

\section{References}

1. Varnik P. Suicide in the world. Int J Environ Res Public Health. 2012; 9(3):760-771.
2. Phillips MR, Li X, Zhang Y. Suicide rates in China, 1995-1999. Lancet. 2002;359(9309):835-840.

3. Yip PS, Liu KY, Hu J, Song XM. Suicide rates in china during a decade of rapid social changes. Soc Psychiatry Psychiatr Epidemiol. 2005; 40(10):792-798.

4. Yang GH, Zhou LN, Huang ZJ, Chen AP. [The trend and geographic distribution of suicide in Chinese population]. Zhonghua Liu Xing Bing Xue Za Zhi. 2004;25(4):280-284.

5. Ji J, Kleinman A, Becker AE. Suicide in contemporary China: a review of China's distinctive suicide demographics in their sociocultural context. Harv Rev Psychiatry. 2001;9(1):1-12.

6. Zhang J, Ma J, Jia C, et al. Economic growth and suicide rate changes: a case in China from 1982 to 2005. Eur Psychiatry. 2010;25(3):159-163.

7. Liu S, Page A, Yin P, et al. Spatiotemporal variation and social determinants of suicide in China, 2006-2012: findings from a nationally representative mortality surveillance system. Psychol Med. 2015;45(15): 3259-3268.

8. Yang GH, Phillips MR, Zhou MG, Wang LJ, Zhang YP, Xu D. Understanding the unique characteristics of suicide in China: national psychological autopsy study. Biomed Environ Sci. 2005;18(6):379-389.

9. He ZX, Lester D. Sex ratio in Chinese suicide. Percept Mot Skills. 2002; 95(2):620.

10. Qin P, Mortensen PB. Specific characteristics of suicide in China. Acta Psychiatr Scand. 2001;103(2):117-121.

11. Yip PS, Callanan C, Yuen HP. Urban/rural and gender differentials in suicide rates: east and west. J Affect Disord. 2000;57(1-3):99-106.

12. Mann JJ, Waternaux C, Haas GL, Malone KM. Toward a clinical model of suicidal behavior in psychiatric patients. Am J Psychiatry. 1999; 156(2):181-189.

13. Phillips MR, Yang G, Zhang Y, Wang L, Ji H, Zhou M. Risk factors for suicide in China: a national case-control psychological autopsy study. Lancet. 2002;360(9347):1728-1736.

14. Hintikka J, Saarinen PI, Viinamaki H. Suicide mortality in Finland during an economic cycle, 1985-1995. Scand J Public Health. 1999;27(2): $85-88$.

15. Lucey S, Corcoran P, Keeley HS, Brophy J, Arensman E, Perry IJ. Socioeconomic change and suicide: a time-series study from the Republic of Ireland. Crisis. 2005;26(2):90-94.

16. Tapia Granados JA. Increasing mortality during the expansions of the US economy, 1900-1996. Int J Epidemiol. 2005;34(6):1194-1202.

17. Kwon JW, Chun H, Cho SI. A closer look at the increase in suicide rates in South Korea from 1986-2005. BMC Public Health. 2009;9:72.

18. Stuckler D, Basu S, Suhrcke M, Coutts A, McKee M. The public health effect of economic crises and alternative policy responses in Europe: an empirical analysis. Lancet. 2009;374(9686):315-323.

19. Zivin K, Paczkowski M, Galea S. Economic downturns and population mental health: research findings, gaps, challenges and priorities. Psychol Med. 2011;41(7):1343-1348.

20. Nandi A, Prescott MR, Cerda M, Vlahov D, Tardiff KJ, Galea S. Economic conditions and suicide rates in New York City. Am J Epidemiol. 2012;175(6):527-535.

21. Saurina C, Marzo M, Saez M. Inequalities in suicide mortality rates and the economic recession in the municipalities of Catalonia, Spain. Int J Equity Health. 2015;14:75.

22. Perkins DH. Rapid growth and changing economic structure: the expenditure side story and its implications for China. China Econ Rev. 2012;23:501-511.

23. Wang CW, Chan CL, Yip PS. Suicide rates in China from 2002 to 2011: an update. Soc Psychiatry Psychiatr Epidemiol. 2014;49(6):929-941.

24. Zhou M, Jiang Y, Huang Z, Wu F. Adjustment and representativeness evaluation of national disease surveillance points system. Dis Surveillance. 2010;25(3):239-244.

25. Lopez AD, Mathers CD, Ezzati M, Jamison DT, Murray CJL. Measuring the global burden of disease and risk factors, 1990-2001. In: Lopez AD, Mathers CD, Ezzati M, Jamison DT, Murray CJL, editors. Global Burden of Disease and Risk Factors. Oxford University Press: Washington, DC: 2006. 
26. Ver Hoef JM, Boveng PL. Quasi-poisson vs. negative binomial regression: how should we model overdispersed count data? Ecology. 2007;88(11):2766-2772.

27. Yip PS, Liu KY, Law CK. Years of life lost from suicide in China, 1990-2000. Crisis. 2008;29(3):131-136.

28. Zhang L, Li Z, Li X, et al. Study on the trend and disease burden of injury deaths in Chinese population, 2004-2010. PLoS One. 2014;9(1): e85319.

29. Cai Y, Hu N, Liu YN, Wang L. Analysis on suicide mortality in China population 2010. Chin Prev Med. 2012;6:480-482.

30. World Health Organization. Preventing Suicide: A Global Imperative. Geneva: World Health Organization; 2014.

31. Zhou M, Wang H, Zhu J, et al. Cause-specific mortality for 240 causes in China during 1990-2013: a systematic subnational analysis for the global burden of disease study 2013. Lancet. 2015;387(10015):251-272.
32. Zhang J, Jun J, Xueya W, Weiwei S, Cuntong W. A sociological analysis of the decline in the suicide rate in China. Soc Sci China. 2011;2011(5): 97-113.

33. Hill SA, Pritchard C, Laugharne R, Gunnell D. Changing patterns of suicide in a poor, rural county over the 20th century: a comparison with national trends. Soc Psychiatry Psychiatr Epidemiol. 2005;40(8): 601-604.

34. Kapusta ND, Zorman A, Etzersdorfer E, Ponocny-Seliger E, Jandl-Jager E, Sonneck G. Rural-urban differences in Austrian suicides. Soc Psychiatry Psychiatr Epidemiol. 2008;43(4):311-318.

35. Inoue K, Fukunaga T, Okazaki Y. Study of an economic issue as a possible indicator of suicide risk: a discussion of stock prices and suicide. J Forensic Sci. 2012;57(3):783-785.

36. Stack S, Wasserman I. Economic strain and suicide risk: a qualitative analysis. Suicide Life Threat Behav. 2007;37(1):103-112.

\section{Publish your work in this journal}

Neuropsychiatric Disease and Treatment is an international, peerreviewed journal of clinical therapeutics and pharmacology focusing on concise rapid reporting of clinical or pre-clinical studies on a range of neuropsychiatric and neurological disorders. This journal is indexed on PubMed Central, the 'PsycINFO' database and CAS, and is the official journal of The International Neuropsychiatric Association (INA). The manuscript management system is completely online and includes a very quick and fair peer-review system, which is all easy to use. Visit http://www.dovepress.com/testimonials.php to read real quotes from published authors. 